\title{
Quality aspects of coffees and teas: Application of electron paramagnetic resonance (EPR) spectroscopy to the elucidation of free radical and other processes
}

\author{
Bernard A. Goodman ${ }^{1^{*}}$, Chahan Yeretzian ${ }^{2}$, Klaus Stolze $^{3}$, Deng Wen ${ }^{4}$ \\ ${ }^{1}$ State Key Laboratory for Conservation and Utilization of Subtropical Agro-Bioresources, Guangxi University, Nanning, China; \\ *Corresponding Author: bernard a goodman@yahoo.com \\ ${ }^{2}$ Zurich University of Applied Sciences, Institute of Chemistry and Biological Chemistry, Wädenswil, Switzerland \\ ${ }^{3}$ Institute of Pharmacology and Toxicology, Dept. Biomedical Sciences, University of Veterinary Medicine, Vienna, Austria \\ ${ }^{4}$ Department of Physics, Guangxi University, Nanning, China
}

Received 17 April 2013; revised 18 May 2013; accepted 15 June 2013

Copyright (C) 2013 Bernard A. Goodman et al. This is an open access article distributed under the Creative Commons Attribution License, which permits unrestricted use, distribution, and reproduction in any medium, provided the original work is properly cited.

\begin{abstract}
Coffees and teas are beverages that are both exceptionally rich in antioxidant molecules, and are also both associated with beneficial health effects. Thus although the quality characteristics of these beverages are conventionally assessed on the basis of their sensory properties, their antioxidant contents represent an additional and increasingly valued attribute of quality based on their contributions to healthy diets.

Both beverages are prepared by hot water extraction of a pure plant-derived product, and thus their compositions can potentially change quite rapidly as a result of oxidation in contact with air. Oxidative processes often proceed via free radical intermediates, and sometimes also result in the formation of stable radical endproducts; thus EPR spectroscopy is a convenient technique for investigating some of the various free radical reactions that occur in these beverages. This paper reviews progress that has been made in elucidating free radical processes that occur during the preparation and storage of coffees and teas, and the results are discussed in terms of quality criteria of the beverages.
\end{abstract}

Keywords: Coffee; Tea; Free Radicals; Antioxidants; EPR Spectroscopy; Quality

\section{INTRODUCTION}

Coffees and teas are two of the most heavily consumed beverages in the World. Both have a history of links to medicinal properties, although neither is conventionally considered to be a traditional medicine. Conventionally the qualities of teas and coffees are assessed on the basis of their sensory properties by expert panels of tasters, as these are relevant to the primary and direct/immediate experiences of consumers. Yet, we have learned over recent years that both beverages contain molecules that are considered to be beneficial to long-term health and well-being, a quality that is increasingly noticed and valued by consumers. Hence our definition and understanding of quality in coffee and tea are slowly but sustainably being extended to one that contains long term health benefits in addition to the immediate sensory impact.

The major beneficial molecules belong to a class of compound known as antioxidants, whose principal function in biology is to protect cells from oxidative damage. They do this in one of three ways; 1) by inhibiting the formation of oxidizing agents, 2) by selectively scavenging oxidizing agents, or 3) by scavenging the products of the reactions of oxidizing agents, which may themselves be capable of causing cellular damage. Mechanism 1) generally involves antioxidant enzymes, whereas 2) and 3) may be performed by either small or large molecules. However, a common property of biological antioxidants is their ability to redox cycle between reduced and oxidized forms, both of which are generally stable.

The stable form of molecular oxygen, ${ }^{3} \mathrm{O}_{2}$, is a free radical with two unpaired electrons, and various products derived from it are known as reactive oxygen species (ROS), because they tend to be more reactive than $\mathrm{O}_{2}$ itself. Some of these are also free radicals, including the 
products of its 1-electron reduction, $\mathrm{O}_{2}^{-}$and its protonated form $\mathrm{OOH}$, as well as the hydroxyl radical $\mathrm{OH}$, whereas others, such as its unstable form, ${ }^{1} \mathrm{O}_{2}$, and hydrogen peroxide, $\mathrm{H}_{2} \mathrm{O}_{2}$, are diamagnetic. However, both ${ }^{1} \mathrm{O}_{2}$ and $\mathrm{H}_{2} \mathrm{O}_{2}$ readily participate in reactions that lead to free radical generation, and free radicals are a common feature of biological oxidation processes. Thus antioxidants are often assumed to be free radical scavengers, and although this is an oversimplification of their chemical behavior, there are close links between antioxidants and the control of free radical reactions in biological and complex food systems.

Since coffee and tea are the major sources of antioxidants in many diets (e.g. [1,2]) and may also be stored for long periods in air, it might be expected that oxidation processes could influence their antioxidant contents, or at the very least result in changes in their forms which could impact on the chemical composition of the beverages subsequently prepared by hot water extraction. However, such reactions are extremely complex, and it is only now that we are starting to develop an understanding of the various chemical processes that are involved. The current paper addresses various aspects of the beverage production in which $\mathrm{O}_{2}$-derived free radicals are involved, and illustrates these with results obtained using electron paramagnetic resonance (EPR) spectroscopy, a technique which is based on measurements of chemical species with unpaired electrons, such as free radicals and paramagnetic metal ions and complexes.

\section{ANTIOXIDANTS AND FREE RADICAL SPECIES IN COFFEE PRODUCTION}

Although coffee is most commonly associated with the alkaloid caffeine, which has been considered to have some antioxidant properties as a result of its conversion to oxocaffeine (1-methyl uric acid) during coffee oxidation [3], there are other bioactive compounds in the bev- erage. Furthermore, caffeine is not a true antioxidant because oxocaffeine formation in the beverage is probably the result of reaction with hydroxyl radicals, which react virtually indiscriminately with organic molecules.

Green coffee beans are a rich source of chlorogenic acids, a family of polyphenol antioxidants that feature in a number of traditional Asian medicines (e.g. [4,5]), and to which beneficial health effects from the consumption of coffee have been attributed [6]. The chlorogenic acids (Figure 1) are esters of quinic acid and various polyphenols, but mainly caffeic, $p$-coumaric and ferulic acids $[7,8]$. Various mono-, di- and tri-esters exist and 70 different chlorogenic acids have been identified in extracts of green coffee beans [9].

The major changes to coffee beans that occur during roasting are the formation of melanoidins, ill-defined colored materials, via the Maillard and caramelization reactions. The Maillard reaction involves a condensation reaction between free amino groups of amino acids, peptides or proteins with carbonyl groups of reducing sugars, whereas the caramelization reaction is based on reactions involving sugars or carbohydrates alone. However, both reactions are extremely complex and result in the generation of a wide range of products, including the melanoidins. Although melanoidins have been described as possessing mutagenic activity $[10,11]$, they are also associated with beneficial health properties (e.g. [12]). Furthermore, the Maillard reaction produces compounds with strong antioxidant properties [13], and coffee is overall described as being anticarcinogenic $[14,15]$.

Understanding the chemistry of the coffee roasting process is a major challenge, but one that is necessary in order to refine existing procedures to produce higher quality products. During roasting, the contents of chlorogenic acids decrease, although some are incorporated into the melanoidin components from which they may subsequently be released during digestion [16]. However,

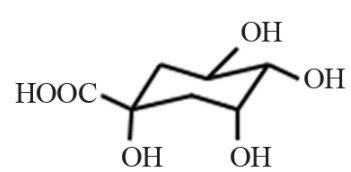

quinic acid

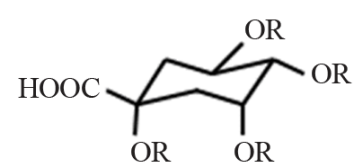

chlorogenic acid<smiles>O=C(O)/C=C/c1ccc(O)cc1</smiles>

p-coumaric acid<smiles>O=C(O)/C=C/c1ccc(O)c(O)c1</smiles>

caffeic acid<smiles>COc1cc(/C=C/C(=O)O)ccc1O</smiles>

ferulic acid

Figure 1. Chemical structures of chlorogenic acids; these are esters of quinic acid and 1 or more phenolic acids, such as p-coumaric, caffeic or ferulic acid/. 
because of the antioxidant properties of melanoidins, the roasting process results in an overall increase in the antioxidant content of the beverage, with maximum activity being reported for medium roasted beans [17,18]. The roasting of coffee also results in the formation of substantial quantities of free radicals (e.g. [19]), the contents of which are influenced by a number of factors including the water content of the green beans prior to roasting [20].

It is in addressing issues involving free radicals and other paramagnetic chemical species that EPR spectroscopy can make important contributions to the science of coffee. Changes in free radical concentrations can be monitored in essentially real time in an EPR spectrometer (Figure 2) [21], and thus this technique allows the possibility of investigating how variables such as the temperature profile and gas flow rate influence free radical concentrations during the roasting process for different bean types.

The formation of both antioxidant molecules and free radicals during the coffee roasting process demonstrates that the two processes are not inversely related, as might be expected if the principal role for antioxidants was to inhibit the production of, or to selectively scavenge, free radicals. Indeed, with commercial "instant" coffees, Pascual et al. [22] showed that there was no correlation between their antioxidant and free radical contents.

\section{OXIDATIVE PROCESSES DURING THE STORAGE OF ROASTED COFFEE PRODUCTS}

Oxidative processes influence the composition of roasted coffees during subsequent storage, as evidenced by increases in their levels of lipid peroxidation [23-25]. Furthermore, storage in air results in a progressive increase in the EPR free radical signal [26], whereas in the absence of air a progressive decrease is observed [27]. These results thus illustrate that the roasted coffee is not an inert material, and that changes in the free radical components are the result of processes that involve both formation and decay. In addition, the recent work of Yeretzian et al. [26] has demonstrated that the increase in free radical signal during storage in air of roasted and ground $(\mathrm{R} \& \mathrm{G})$ coffee is mainly the result of reaction of coffee components with $\mathrm{O}_{2}$ and not directly the result of physical damage caused by the grinding process.

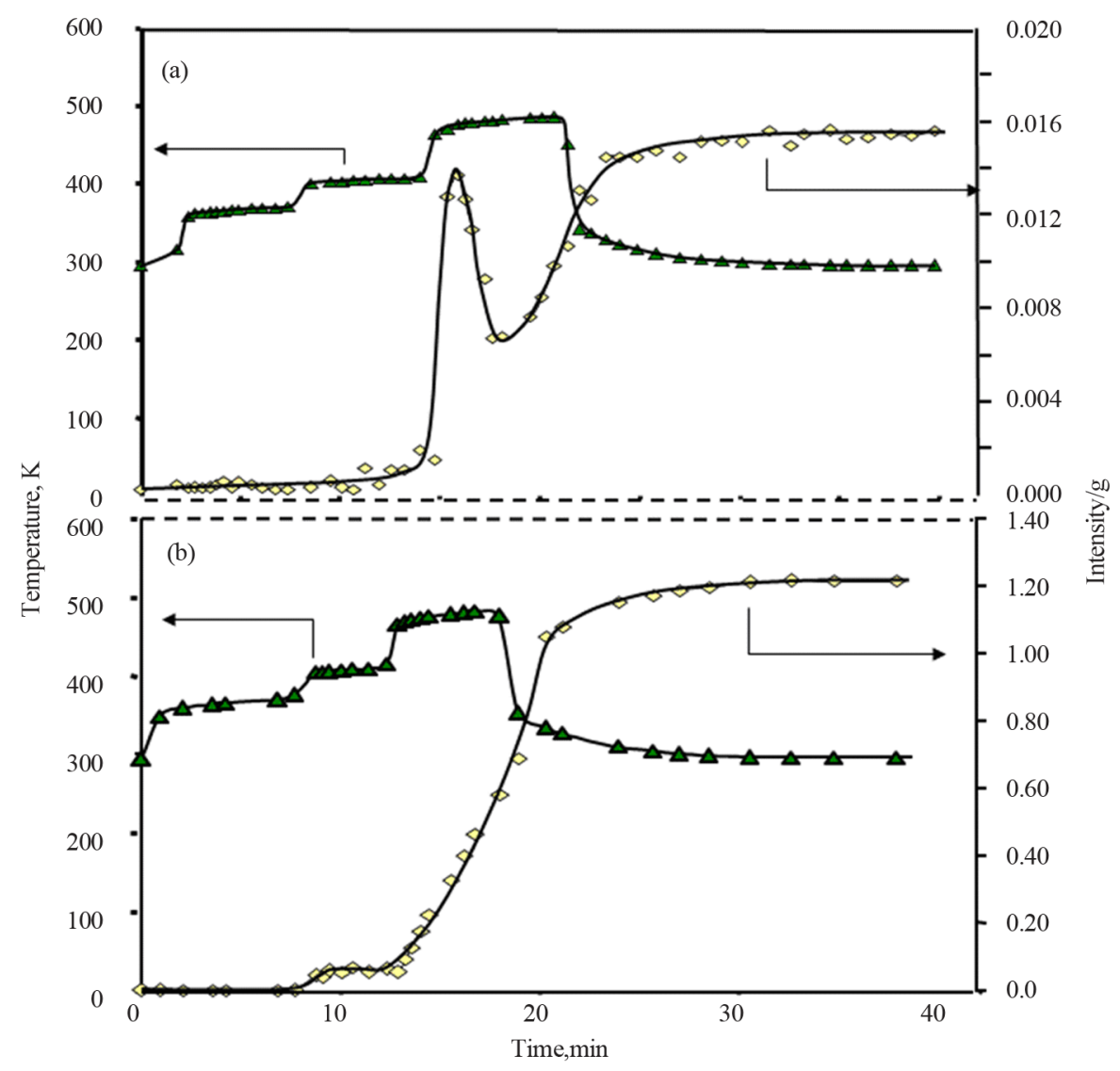

Figure 2. Profiles for EPR free radical signal intensities during the roasting in $\mathrm{N}_{2}$ of (a) Robusta and (b) Arabica coffee beans (adapted from reference [21]). Note the much higher free radical concentration in Arabica beans. 


\section{FREE RADICAL REACTIONS IN COFFEE BEVERAGES}

After preparation, the sensory characteristics of coffee beverages change rapidly. EPR measurements show that changes in free radical contents also occur, and although "cause and effect" relationships have not been established it seems likely that hydroxyl radicals are involved, because of the presence in coffee of the chemical components appropriate for Fenton reaction chemistry [28]. With solutions of "instant" coffee, Pascual et al. [29] described a temperature independent decay of the initial free radical signal on a timescale similar to that observed by Hofmann et al. [30] for the radicals formed on dissolution in water of 1,4-dialkylpyrazinium diquaternary salts (diquat), which are early products of the Maillard reaction. However, Pascual et al. [29] also observed a temperature dependent production of a free radical signal with similar spectral characteristics to that of the original radical, a result which indicates that free radical reactions occur continuously in the coffee beverage. Furthermore, these authors also demonstrated that $\mathrm{O}_{2}$ was involved in the production of this new signal, possibly as a source of hydroxyl radicals by enzymatic conversion to $\mathrm{H}_{2} \mathrm{O}_{2}$ [31] followed by Fenton reaction chemistry. Although chemical spin trapping combined with EPR spectroscopy is a recognized method for the identification of unstable free radical intermediates (e.g. [32]), the results of such measurements indicated the trapping of $\mathrm{C}$-centred radicals. However, unlike the superoxide radical anion $\left(\mathrm{O}_{2}^{-}\right)$, the hydroxyl radical reacts virtually indiscriminately with organic molecules. Thus in complex systems such as coffee solutions, most of these radicals will react via hydrogen atom extraction with organic components in the beverage and it is the resulting $\mathrm{C}$-centred radicals that are observed after reaction with the spin trap.

\section{PROBLEMS ASSOCIATED WITH THE STORAGE OF LIQUID COFFEE PRODUCTS}

As mentioned in the previous paragraph, the sensory properties change rapidly after preparation of coffee beverages. In addition to shedding light on the short term radical processes that occur in the beverage, EPR spectroscopy has also been shown to be potentially useful in understanding processes that occur during longer term storage of liquid coffee products under controlled conditions. Recently, Pascual et al. [33] have used EPR spectroscopy to investigate the effects of various factors that affect the stability of liquid coffee prepared from aqueous extracts of whole roasted coffee beans. They found that the free radical EPR signal intensity is sensitive to the $\mathrm{O}_{2}$ content of the water used for extraction and the storage temperature, but not the storage atmosphere (headspace). In similar measurements on concentrated coffee solutions, Yeretzian et al. [34] (2013) also observed that the $\mathrm{O}_{2}$ content of the water used for extraction was the largest factor which affected the changes in the free radical EPR signal during storage. However, whereas the intensities of the signal from whole bean extracts increased during storage, those from coffee concentrates decreased, thus indicating the difficulties in producing simple interpretations of the results from such measurements.

\section{DEGRADATION OF COFFEE AROMA}

The aroma of coffee that is generated during the roasting process is considered to be one of the most attractive features of the beverage, and it is generally considered to represent an important quality criterion. However, its chemical composition is extremely complex, and represents the combination of many hundreds (thousands?) of molecules, each of which is present in small concentration [35]. Furthermore, several key aroma molecules, especially those containing thiol groups, have limited stability with respect to oxidation, and as a result the sensory properties decline during storage. One such molecule is furfuryl mercaptan, and its decomposition under Fenton reaction conditions has been investigated in detail by Blank et al. [36]. This reaction was found to be extremely complex and involved the generation of both Cand S-centred radical species in early stages of the degradation process.

An $a b$ initio computational approach to explore the stability of a wide range of coffee aroma compounds has been reported by Munro et al. [37]. These studies focused on the various free radical processes that might lead to aroma degradation during storage of liquid coffee, and involved investigation of $>100$ radicals that might be formed during the reactions of key aroma compounds. These radical products were classified according to their thermodynamic stabilities relative to common radical sources that might exist in liquid coffee extracts. The results predicted that most aroma molecules should be resistant to both peroxidation and attack from phenolic antioxidants, but are unstable with respect to reaction with $\bullet \mathrm{OH}$.

\section{ANTIOXIDANTS IN TEA LEAVES AND THEIR CHANGES DURING PROCESSING}

The tea beverage is prepared by hot water extraction of dried leaves of the plant Camellia sinensis. Different types of tea are classified according to the degree of processing to which the leaves are subjected prior to packaging, with the amount of oxidation increasing in the order white $\approx$ green $<$ red $<$ black (Note the Chinese red tea is roughly equivalent to the Indian black tea, 
whereas the Chinese Pu'er tea is a black tea that is allowed to undergo some fermentation before being processed). The stability (shelf life) of the products follows a similar trend and Pu'er tea is stable over many decades.

All teas contain substantial quantities of polyphenolic antioxidants, but their molecular compositions and sizes increase according to the degree of oxidation they experience during processing. Thus the polyphenols in the lightly processed white and green teas are dominated by relatively simple catechins, known as green tea polyphenols (GTP); the major GTP are (-)-epigallocatechin gallate (EGCG), (-)-epigallocatechin (EGC), (-)-epicatechin gallate (ECG), (-)-epicatechin (EC), and (+)-catechin (CT) (Figure 3). In addition, gallic acid (GA) may also be observed. In contrast, the dominant polyphenols in black teas the more complex theaflavins, thearubigins and more highly polymerized substances [38]. The GTP have received considerable attention for the association of green tea consumption with beneficial health properties (e.g. [39-42]), but there is evidence that the various types of tea have similar beneficial health effects $[43,44]$.

\section{AUTOXIDATION REACTIONS IN TEAS}

As mentioned in the previous section, teas contain appreciable quantities of polyphenols, which are generally assumed to be responsible for the beneficial health effects of the beverage. During their behavior as antioxidants, polyphenols are oxidized to phenoxy or more commonly semiquinone radicals, and this reaction proceeds more rapidly at high $\mathrm{pH}$ values. Consequently, alkaline autoxidation is often used as an experimental procedure for accelerated oxidation in order to under- stand the chemistry of the tea polyphenols. Under such conditions, EPR spectra can be readily observed (Figure 4), and results show that signals are observed from each of the main green tea polyphenols in alkaline solutions of green tea extracts (e.g. [45-47]), whereas the spectra from equivalent black tea samples are dominated by the radical corresponding to oxidized gallic acid $[45,46]$. Thus there may be considerable differences in the antioxidant chemistry reactions of different types of tea, and EPR could be a useful technique for comparing reactions in teas that have been subjected to different types of processing. However, caution needs to be exercised in extrapolating results from alkaline autoxidation to reactions under physiological conditions, since oxidation of EGCG by superoxide at near neutral $\mathrm{pH}$ values proceeds via a different mechanism to that observed on alkaline autoxidation [47].

An important property of plant-derived polyphenols is their ability to function as antimicrobial molecules [4852]. However, the microbial degradation of white/green tea leaves has a major effect not just on the easily oxidizable GTP, but also other compounds such as caffeine, which generally are not susceptible to alteration during storage (Klaus Stolze, unpublished results). This then represents another example of complex chemical behaveior in a beverage that needs to be investigated further.

\section{OTHER MOLECULES IN TEA EXTRACTS THAT COULD CONTRIBUTE TO THEIR BIOACTIVITY}

The potentially beneficial molecules in teas are not limited to their polyphenolic components, and other bio-<smiles>Oc1cc(O)c2c(c1)O[C@H](c1ccc(O)c(O)c1)[C@H](O)C2</smiles><smiles>Oc1cc(O)c2c(c1)O[C@H](c1ccc(O)c(O)c1)[C@H](O)C2</smiles>

(-)-epigallocatechin (EGC)<smiles>Oc1cc(O)c2c(c1)O[C@H](c1cc(O)c(O)c(O)c1)[C@H](O)C2</smiles><smiles>O=C(O[C@H]1Cc2c(O)cc(O)cc2O[C@H]1c1ccc(O)c(O)c1)c1cc(O)c(O)c(O)c1</smiles><smiles>O=C(O[C@H]1Cc2c(O)cc(O)cc2O[C@H]1c1cc(O)c(O)c(O)c1)c1cc(O)c(O)c(O)c1</smiles>

Figure 3. Chemical structures of the green tea polyphenols (-)-epicatechin (EC), (+)catechin (CT), (-)-epigallocatechin (EGC), (-)-epicatechin gallate (ECG), and (-)epigallocatechin gallate (EGCG). 


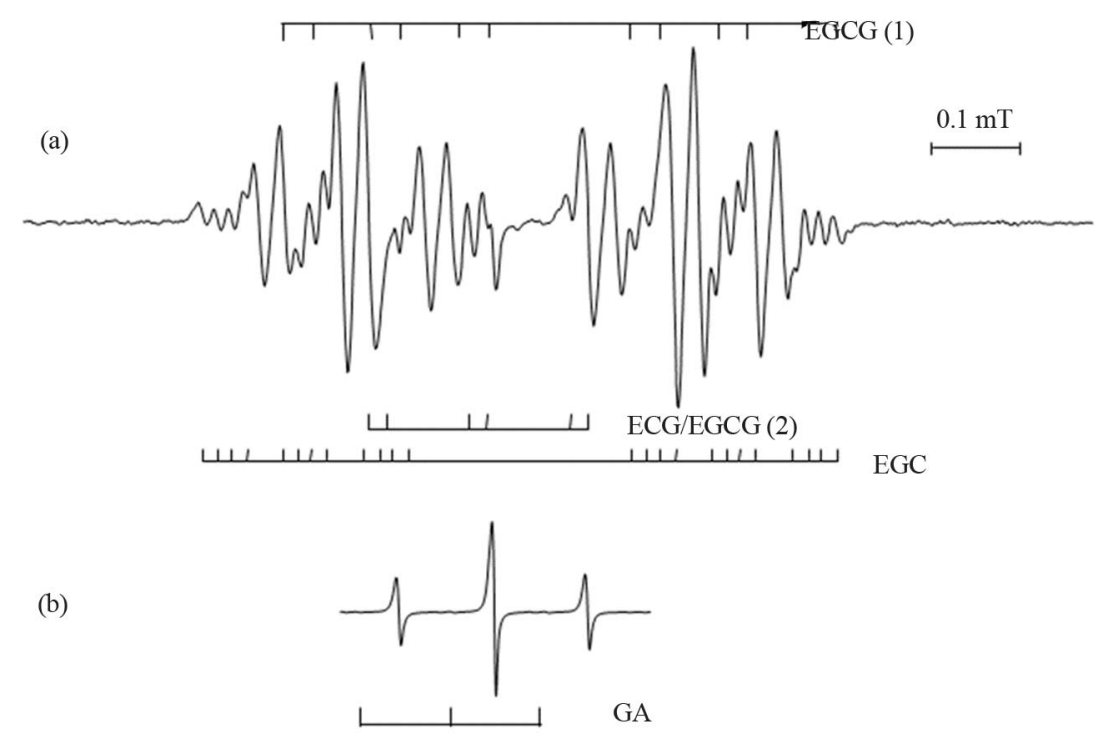

Figure 4. EPR spectra of autoxidized (a) green tea and (b) black (Pu'er) tea. Details of the interpretation of the green tea spectrum are given in reference [47].

active molecules are present in the beverage. As with coffee, caffeine is a significant component, albeit at appreciably lower concentrations than in coffee [38]. The principal amino acid in tea is theanine (5-N-ethylglutamine) [53,54], which has been shown to be effective in reducing mental and physical stress [55] and to improving cognition in impaired subjects [56]. It has also been proposed to be able to provide protection against dementia [57], and is thus complementary to caffeine in its effects on neurodegeneration. Furthermore, although the neurological effects associated with tea consumption have been attributed to the metal chelating properties of EGCG (by inhibiting the formation of $\beta$-amyloid plaques) [58], there is little soluble chelate formation on reaction of $\mathrm{Cu}(\mathrm{II})$ with the GTP EGCG and GA at neutral and acidic $\mathrm{pH}$ values $[59,60]$. In contrast, the teas themselves are able to form soluble $\mathrm{Cu}$ (II) complexes over a wide range of $\mathrm{pH}$ values $[46,61]$. Thus it seems likely that molecules in tea other than the GTP are responsible for metal chelation under physiological conditions. Theanine does form $\mathrm{Cu}$ (II) complexes under acidic conditions but Goodman et al. [61] have reported the presence of an additional (as yet unidentified) compound in teas that can form complexes with $\mathrm{Cu}(\mathrm{II})$ at $\mathrm{pH}<2$.

\section{GENERAL DISCUSSION, CONCLUSIONS AND FORWARD LOOK}

We are only now starting to get an appreciation of the roles played by antioxidants and free radical reactions in the chemistry of coffees and teas, but their relationships to conventional quality assessment based on sensory properties are still largely uninvestigated. However, it is now recognized that foods rich in antioxidants are associated with beneficial health properties, and consequently both coffees and teas can make valuable contributions to healthy diets.

In coffees, the main antioxidants are the chlorogenic acids and melanoidins, with the relative importance of these two groups of molecule being dependent on both the plant genetics and the darkness of the roast. The medicinal properties of chlorogenic acids are well known (e.g. $[4,5])$, and these molecules feature in a number of traditional Asia medicines, but there is still controversy concerning the biological effects of the melanoidins. Thus these molecules need further investigation and characterization, but this is a highly challenging research field because of the ill-defined nature and large molecular sizes of this family of molecules.

In teas, it is generally accepted that the beneficial properties are derived from the polyphenolic components. However, their chemical nature varies according to the post-harvest processing to which the tea leaves are subjected, and it is only the GTP that has been studied in detail. Nevertheless, the antioxidant properties of green and black tea are similar [62], and epidemiological studies suggest that their beneficial health effects are also similar $[43,44]$. Furthermore, teas also contain other bioactive molecules, such as theanine, and also some as yet unidentified molecules with the ability to chelate metal ions such as $\mathrm{Cu}(\mathrm{II})$ at very low $\mathrm{pH}$ values $[46,61]$.

As described in this paper, EPR spectroscopy is able to make appreciable contributions to developing our understanding of free radical aspects of the chemistry of coffee and teas. However, this approach to the research is still in its infancy and more progress is expected in the near future from further applications of the technique. 
Firstly, EPR provides an opportunity to investigate in real time the formation and reaction of free radicals during the roasting process. However, as yet few studies have been performed, and more investigations are needed to understand the influence of various factors such as plant genetics, bean age, roasting temperature profiles, gas flow rates, water contents of the green beans, etc. In addition, such measurements should be combined with or related to parallel measurements of the emission of volatile organic compounds, as reported by Dorfner et al. $[63,64]$ and Wieland et al., [65] using on-line ProtonTransfer-Reaction Mass-Spectrometry.

Further investigations of the relative importance of various environmental factors on the changes that occur during the storage of roasted coffees are still needed, because the various studies that have been reported to date have been based on relatively small data sets. Considering the large differences in free radical generation observed by Goodman et al. [21] for individual beans during a batch roasting of a blend of coffee beans of different origin, it also seems possible that there could be correspondingly large differences in the behavior of different types of bean during storage.

Understanding the solution chemistry of both coffee and tea beverages is a long-standing problem, and although progress is being made there is still much that remains unknown. With both beverages, oxidation processes originating from exposure to $\mathrm{O}_{2}$ result in progressive alteration of the beverages. It seems likely that Fenton reaction chemistry plays an important role, and because of the highly reactive nature of the hydroxyl radical, antioxidants and/or free radical scavengers are ineffective in inhibiting its reactions. Thus the most effective approach to stability of solutions of these beverages would appear to be strict exclusion of $\mathrm{O}_{2}$ at various critical stages of their preparation. Recent preliminary results $[33,34]$ suggest that may be the case for coffee, but more detailed studies on teas are still required.

Also with teas, further measurements are required on red and black teas in order to relate details of their chemistry to that of green tea, which has been studied in much greater detail. This should not just address the chemistry of the polyphenols, but should also consider the identity and reactions of other low molecular weight molecules that could contribute to the bioactivity of the beverage.

\section{ACKNOWLEDGEMENTS}

Many of the EPR results used in this paper were obtained with facilities at either the Scottish Crop Research Institute or the Austrian Institute of Technology who are gratefully acknowledged. In addition, the Nestlé Research Center (NRC) is thanked for supplying and preparing the liquid coffee specimens. Finally, we wish to recognize the valuable contributions made by Drs Ederlinda C. Pascual, Katharina F. Pirker and Joyce Ferreira Severino in developing the original scientific measurements.

\section{REFERENCES}

[1] Pulido, R., Hernández-García, M. and Saura-Calixto, F. (2003) Contribution of beverages to the intake of lipophilic and hydrophilic antioxidants in the Spanish diet. European Journal of Clinical Nutrition, 57, 1275-1282. doi:10.1038/sj.ejen.1601685

[2] Svilaas, A., Kaur Sakhi, A., Frost Andersen, L., Svilaas, T., Ström, E.C., Jacobs Jr., D.R. Ose, L. and Blomhoff, R. (2004) Intakes of antioxidants in coffee, wine, and vegetables are correlated with plasma carotenoids in humans. Journal of Nutrition, 134, 562-567.

[3] Stadler, R.H. and Fay, L.B. (1995) Antioxidative reactions of caffeine: Formation of 8-oxocaffeine (1,3,7trimethyluric acid) in coffee subjected to oxidative stress. Journal of Agricultural and Food Chemistry, 43, 13321338. doi:10.1021/jf00053a038

[4] Zhao, Y.K., Cao, Q.E., Liu, H.T., Wang, K.T., Yan, A.X. and Hu, Z.D. (2000) Determination of baicalin, chlorogenic acid and caffeic acid in traditional Chinese medicinal preparations by capillary zone electrophoresis. Chromatographia, 51, 483-486. doi:10.1007/BF02490489

[5] Chen, X.F., Zhang, J.U., Xue, C.X., Chen, X.G. and Hu, Z.D. (2004) Simultaneous determination of some active ingredients in anti-viral preparations of traditional Chinese medicine by micellar electrokinetic chromatography. Biomedical Chromatography, 18, 673-680. doi:10.1002/bmc.373

[6] Higdon, J.V. and Frei, B. (2006) Coffee and health: A review of recent human research. Critical Reviews in Food Science and Nutrition, 46, 101-123. doi:10.1080/10408390500400009

[7] Clifford, M.N. (1999) Chlorogenic acids and other cinnamates-Nature, occurrence and dietary burden. Journal of the Science of Food and Agriculture, 79, 362-372. doi:10.1002/(SICI)1097-0010(19990301)79:3<362::AIDJSFA256>3.0.CO;2-D

[8] Clifford, M.N. (2000) Chlorogenic acids and other cinnamates - Nature, occurrence, dietary burden, absorption and metabolism. Journal of the Science of Food and Agriculture, 80, 1033-1043.

doi:10.1002/(SICI)1097-0010(20000515)80:7<1033::AI D-JSFA595>3.0.CO;2-T

[9] Kuhnert, N. and Jaiswal, R. (2012) Occurrence and identification of chlorogenic acids in green and roasted coffee beans. In: Goodman, B.A., Ed., Coffee Consumption and Health, Nova Science Publishers, New York, 65-97.

[10] Powrie, W.D., Wu, C.H. and Molund, V.P. (1986) Browning reaction systems as sources of mutagens and antimutagens. Environmental Health Perspectives, 67, 47-54. doi:10.1289/ehp.866747

[11] Kitts, D.D., Wu, C.H., Kopec, A. and Nagasawa, T. (2006) Chemistry and genotoxicity of caramelized sucrose. Molecular Nutrition \& Food Research, 50, 1180-1190. doi:10.1002/mnfr.200600181 
[12] Casal, S. (2012) Coffee roasting; Accurate control for increased bioactivity. In Goodman, B.A., Ed., Coffee Consumption and Health, Nova Science Publishers, New York, 99-119.

[13] Yanagimoto, K., Lee, K.G., Ochi, H. and Shibamoto, T. (2002) Antioxidative activity of heterocyclic compounds found in coffee volatiles produced by Maillard reaction. Journal of Agricultural and Food Chemistry, 50, 54805484. doi:10.1021/if025616h

[14] Obana, H., Nakamura, S. and Tanaka, R. (1986) Suppressive effects of coffee on the SOS responses induced by UV and chemical mutagens. Mutation Research Letters, 175, 47-50. doi:10.1016/0165-7992(86)90124-7

[15] Malaveille, C., Hautefeuille, A., Pignatelli, B., Talaska, G., Vineis, P. and Bartsch, H. (1996) Dietary phenolics as anti-mutagens and inhibitors of tobacco-related DNA adduction in the urothelium of smokers. Carcinogenesis, 17, 2193-2200. doi:10.1093/carcin/17.10.2193

[16] Perrone, D., Farah, A. and Donangelo, C.M. (2012) Influence of Coffee Roasting on the Incorporation of Phenolic Compounds into Melanoidins and Their Relationship with Antioxidant Activity of the Brew. Journal of Agricultural and Food Chemistry, 60, 4265-4275. doi:10.1021/jf205388x

[17] Del Castillo, M.D., Ames, J.M. and Gordon, M.H. (2002) Effect of roasting on the antioxidant activity of coffee brews. Journal of Agricultural and Food Chemistry, 50, 3698-3703. doi:10.1021/jf011702a

[18] Sacchetti, G., Di Mattia, C., Pittia, P. and Mastrocola, D. (2009) Effect of roasting degree, equivalent thermal effect and coffee type on the radical scavenging activity of coffee brews and their phenolic fraction. Journal of Food Engineering, 90, 74-80. doi:10.1016/j.jfoodeng.2008.06.005

[19] O’Meara, J.P., Truby, F.K. and Shaw, T.M. (1957) Free radicals in roasted coffee. Food Research, 22, 96-101. doi:10.1111/j.1365-2621.1957.tb16988.x

[20] Nebesny, E. and Budryn, G. (2006) Changes in free radicals content in coffee beans throughout convective roasting and microwaving and during storage. Deutsche Lebensmittel-Rundschau, 102, 526-530.

[21] Goodman, B.A., Pascual, E.C. and Yeretzian, C. (2011) Real-time monitoring of free radical processes during the roasting of coffee beans using electron paramagnetic resonance spectroscopy. Food Chemistry, 125, 248-254. doi:10.1016/j.foodchem.2010.07.072

[22] Pascual, E.C., Yeretzian, C., Pirker, K.F. and Goodman, B.A. (2005) Antioxidant, pro-oxidant and free radical processes in coffee. In: Zhao, B., Liu, G. and Packer, L., Eds., Natural Antioxidants and Micronutrients, Medimond, Bologna, 119-125.

[23] Nicoli, M.C., Innocente, N., Pittia, P. and Lerici, C.R. (1993) Staling of roasted coffee: Volatile release and oxidation reactions during storage. ASIC 15th International Scientific Colloquium on Coffee, 15, 557-566.

[24] Vila, M.A., Andueza, S., Paz de Peña, M. and Cid, C. (2005) Fatty acid evolution during the storage of ground, roasted coffees. Journal of the American Oil Chemists' Society, 82, 639-646.
[25] Nicoli, M., Calligaris, S. and Manzocco, L. (2009) Shelflife testing of coffee and related products: Uncertainties, pitfalls, and perspectives. Food Engineering Reviews, 1, 159-168. doi:10.1007/s12393-009-9010-8

[26] Yeretzian, C., Pascual, E.C. and Goodman, B.A. (2012) Effect of roasting conditions and grinding on free radical contents of coffee beans stored in air. Food Chemistry, 131, 811-816. doi:10.1016/j.foodchem.2011.09.048

[27] Baesso, M. L., Da Silva, E. C., Vargas, H., Cortez, J. G. and Pelzl, J. (1990). Use of electron spin resonance for the determination of staling of roast coffee in polyethylene bag packs. Zeitschrift für Lebensmittel-Untersuchung und Forschung A, 191, 24-27. doi:10.1007/BF01202360

[28] Winterbourn, C.C. (1995) Toxicity of iron and hydrogen peroxide: the Fenton reaction. Toxicology Letters, 82-83, 969-974. doi:10.1016/0378-4274(95)03532-X

[29] Pascual, E.C., Goodman, B.A. and Yeretzian, C. (2002) Characterisation of free radicals in soluble coffee by electron paramagnetic resonance spectroscopy. Journal of Agricultural and Food Chemistry, 50, 6114-6122. doi:10.1021/jf020352k

[30] Hofmann, T., Bors, W. and Stettmaier, K. (1999) Studies on radical intermediates in the early stage of the nonenzymatic browning reaction of carbohydrates and amino acids. Journal of Agricultural and Food Chemistry, 47, 379-390. doi:10.1021/jf980626x

[31] Öbinger, C., Burner, U. and Ebermann, R. (1997) Generation of hydrogen peroxide by plant peroxidases mediated thiol oxidation. Phyton, 37, 219-226.

[32] Buettner, G.R. and Mason, R.P. (1990) Spin-trapping methods for detecting superoxide and hydroxyl free radicals in vitro and in vivo. In: Packer, L. and Glazer, A.N., Eds., Oxygen Radicals in Biological Systems, Part B, Oxygen Radicals and Antioxidants (Methods in Enzymology, Vol. 186), Academic Press, Inc., San Diego, 127-133.

[33] Pascual, E.C., Yeretzian, C. and Goodman, B.A. (2013) Probing free radical processes during storage of extracts from whole roasted coffee beans: Impact of $\mathrm{O}_{2}$ exposure during extraction and storage. Journal of Agricultural and Food Chemistry (submitted for publication).

[34] Yeretzian, C., Pascual, E.C. and Goodman, B.A. (2013). Effects of $\mathrm{O}_{2}$ during various processing steps on free radical concentrations in hot aqueous extracts of $\mathrm{R} \& \mathrm{G}$ coffee and their changes during storage. Proceedings of the PACCON International Conference, Bangsaen (accepted for publication).

[35] Grosch, W. (2001) Chemistry III: Volatile compounds. In: Clark, R.J. and Vitzthum, O.G., Eds., Coffee: Recent Developments, Blackwell Science, Oxford, 68-89.

[36] Blank, I., Pascual, E.C., Devaud, S., Fay, L.B., Stadler, R.H., Yeretzian, C. and Goodman, B.A. (2002) Degradation of the coffee flavor compound furfuryl mercaptan in model Fenton-type reaction systems. Journal of Agricultural and Food Chemistry, 50, 2356-2364. doi:10.1021/jf011329m

[37] Munro, L.J., Curioni, A., Andreoni, W., Yeretzian, C. and 
Watzke, H. (2003) The elusiveness of coffee aroma: New insights from a non-empirical approach. Journal of Agricultural and Food Chemistry, 51, 3092-3096. doi:10.1021/if0261607

[38] Ho, C.-T. and Zhu, N. (2000). The chemistry of tea. In: Parliament, Ho, C.-T. and Schieberle, P., Eds., Caffeinated Beverages, Health Benefits, Physiological Effects, and Chemistry, ACS Symposium Series 754, ACS, Washington DC, 316-326. doi:10.1021/bk-2000-0754.ch032

[39] Yang, C.S. (1997) Inhibition of carcinogenesis by tea. Nature, 389, 134-135. doi:10.1038/38154

[40] Mukhtar, H. and Ahmad, N. (2000) Tea polyphenols: prevention of cancer and optimizing health. American Journal of Clinical Nutrition, 71, 1698S-1702S.

[41] Hara, Y. (2004) Green tea: Health benefits and applications. Marcel Dekker Inc., New York.

[42] Hodgson, J.M. (2008) Tea flavonoids and cardiovascular disease. Asia Pacific Journal of Clinical Nutrition, 17, 288-290.

[43] Katiyar, S.K. and Mukhtar, H. (1996) Tea in chemoprevention of cancer: Epidemiologic and experimental studies. International Journal of Oncology, 8, 221-238.

[44] Vinson, J.A., Teufel, K. and Wu, N. (2004) Green and black teas inhibit atherosclerosis by lipid, antioxidant, and fibrinolytic mechanisms. Journal of Agricultural and Food Chemistry, 52, 3661-3665. doi:10.1021/jf0352551

[45] Pirker, K.F., Ferreira Severino, J., Reichenauer, T.G. and Goodman, B.A. (2008) Free radical processes in green tea polyphenols (GTP) investigated by electron paramagnetic resonance (EPR) spectroscopy. Biotechnology Annual Review, 14, 349-401. doi:10.1016/S1387-2656(08)00013-6

[46] Goodman, B.A., Ferreira Severino, J., Reichenauer, T.G. and Pirker, K.F. (2009) Aspects of the antioxidant chemistry of teas investigated by electron paramagnetic resonance (EPR) spectroscopy. In: Winyayong, P., Syers, J.K. and Theppakorn, T., Eds., Tea Production and Tea Products, Mae Fah Luang University, Chiang Rai, 101-117.

[47] Ferreira-Severino, J., Goodman, B.A., Kay, C.W.M., Stolze, K., Tunega, D., Reichenauer, T.G. and Pirker, K.F. (2009) Free radicals generated during oxidation of green tea polyphenols: Electron paramagnetic resonance spectroscopy combined with density functional theory calculations. Free Radical Biology and Medicine, 46, 10761088. doi:10.1016/j.freeradbiomed.2009.01.004

[48] Taguri, T., Tanaka, T. and Kouno, I. (2004) Antimicrobial activity of 10 different plant polyphenols against bacteria causing food-borne disease. Biological and Pharmaceutical Bulletin, 27, 1965-1969. doi:10.1248/bpb.27.1965

[49] Moreno, S., Scheyer, T., Romano, C.S. and Vojnov, A.A. (2006) Antioxidant and antimicrobial activities of rosemary extracts linked to their polyphenol composition. Free Radical Research, 40, 223-231. doi:10.1080/10715760500473834

[50] Oliveira, I., Sousa, A., Ferreira, I.C.F.R., Bemto, A., Estevinho, L. and Pereira, J.A. (2008) Total phenols, an- tioxidant potential and antimicrobial activity of walnut (Juglans regia L.) green husks. Food and Chemical Toxicology, 46, 2326-2331. doi:10.1016/i.fct.2008.03.017

[51] Ksouri, R., Falleh, H., Megdiche, W., Trabelsi, N., Mhamdi, B., Chaieb, K.,Bakrouf, A., Magné, C., Abdelly, C. (2009) Antioxidant and antimicrobial activities of the edible medicinal halophyte Tamarix gallica L. and related polyphenolic constituents. Food and Chemical Toxicology, 47, 2083-2091. doi:10.1016/j.fct.2009.05.040

[52] Yaltirak, T., Aslim, B., Ozturk, S. and Alli, H. (2009) Antimicrobial and antioxidant activities of Russula delica Fr. Food and Chemical Toxicology, 47, 2052-2056. doi:10.1016/j.fct.2009.05.029

[53] Cartwright, R.A., Roberts, E.A.H. and Wood, D.J. (1954) Theanine an amino acid of N-ethyl amide present in tea. Journal of the Science of Food and Agriculture, 5, $597-$ 599. doi:10.1002/jsfa.2740051208

[54] Kato, M., Gyoten, Y., Sakai-Kato, K. and Toyo'oka, T. (2003) Rapid analysis of amino acids in Japanese green tea by microchip electrophoresis using plastic microchip and fluorescence detection. Journal of Chromatography A, 1013, 183-189. doi:10.1016/S0021-9673(03)01037-9

[55] Kimura, K., Ozeki, M., Juneja, L. and Ohira, H. (2007) L-Theanine reduces psychological and physiological stress responses. Biological Psychology, 74, 39-45. doi:10.1016/j.biopsycho.2006.06.006

[56] Park, S.K., Jung, I.C., Lee, W.K., Lee, Y.S., Park, H.K., Go, H.J., Kim, K., Lim, N.K., Hong, J.T., Ly, S.Y. and Rho, S.S. (2011) A combination of green tea extract and 1-theanine improves memory and attention in subjects with mild cognitive impairment: A double-blind placebocontrolled study. Journal of Medicinal Food, 14, 334343. doi:10.1089/jmf.2009.1374

[57] Kakuda, T. (2011) Neuroprotective effects of theanine and its preventive effects on cognitive dysfunction. Pharmacological Research, 64, 162-168. doi:10.1016/j.phrs.2011.03.010

[58] Mandel, S., Amit, T., Reznichenko, L., Weinreb, O. and Youdim, M.B.H. (2006) Green tea catechins as brainpermeable, natural iron chelators-antioxidants for the treatment of neurodegenerative disorders. Molecular $\mathrm{Nu}$ trition \& Food Research, 50, 229-234. doi:10.1002/mnfr.200500156

[59] Pirker, K.F., Baratto, M.C., Basosi, R. and Goodman, B.A. (2012) Influence of $\mathrm{pH}$ on the speciation of copper(II) in reactions with the green tea polyphenols, epigallocatechin gallate and gallic acid. Journal of Inorganic Biochemistry, 112, 10-16. doi:10.1016/j.jinorgbio.2011.12.010

[60] Ferreira-Severino, J., Goodman, B.A., Reichenauer, T.G. and Pirker, K.F. (2011) Is there a redox reaction between $\mathrm{Cu}(\mathrm{II})$ and gallic acid? Free Radical Research, 45, 123132. doi: $10.3109 / 10715762.2010 .515220$

[61] Goodman, B.A., Ferreira Severino, J. and Pirker, K.F. (2012). Reactions of green and black teas with $\mathrm{Cu}$ (II). Food \& Function, 3, 399-409. doi:10.1039/c1fo10086f

[62] Leung, L. K., Su, Y., Chen, R., Zhang, Z., Huang, Y. and Chen, Z.-Y. (2001) Theaflavins in black tea and catechins in green tea are equally effective antioxidants. Journal of 
Nutrition, 131, 2248-2251.

[63] Dorfner, R., Ferge, T., Kettrup, A., Zimmermann, R. and Yeretzian, C. (2003) Real-time monitoring of 4-vinylguaiacol, guaiacol and phenol during roasting by resonant laser ionisation time-of-flight mass-spectrometry. Journal of Agricultural and Food Chemistry, 51, 5768-5773. doi:10.1021/jf0341767

[64] Dorfner, R., Ferge, T., Yeretzian, C., Kettrup, A. and Zimmermann, R. (2004) Laser mass spectrometry as on-line sensor for industrial process analysis: Process control of coffee roasting. Analytical Chemistry, 76, 1386-1402. doi:10.1021/ac034758n

[65] Wieland, F., Gloess, A.M., Keller, M., Wetzel, A., Schenker, S. and Yeretzian, C. (2012) On-line monitoring of coffee roasting by proton-transfer-reaction time-of-flight mass-spectrometry (PTR-ToF-MS): Towards a real-time process control for a consistent roast profile. Analytical and Bioanalytical Chemistry, 402, 2531-2543. doi:10.1007/s00216-011-5401-9 